\title{
Locus Ceruleus Activation Suppresses Feedforward Interneurons and Reduces $\beta-\gamma$ Electroencephalogram Frequencies While It Enhances $\theta$ Frequencies in Rat Dentate Gyrus
}

\author{
Robert A. M. Brown, Susan G. Walling, J. Steve Milway, and Carolyn W. Harley \\ Department of Psychology, Memorial University of Newfoundland, St. John's, Newfoundland, Canada A1B 3X9
}

\begin{abstract}
The locus ceruleus is activated by novel stimuli, and its activation promotes learning and memory. Phasic activation of locus ceruleus neurons by glutamate enhances the dentate gyrus population spike amplitude and results in long-term potentiation of synaptic responses recorded after $24 \mathrm{~h}$. Cholinergic activation of locus ceruleus neurons increases hippocampal $\theta$. At the level of the cellular network, it is not clear how the potentiating effects of norepinephrine are mediated. Previous studies show that exogenous norepinephrine enhances inhibitory interneuron firing in the dentate gyrus. This finding appears at odds with evidence for potentiation. In this study, natural release of norepinephrine was induced by glutamate activation of locus ceruleus while we recorded EEGs and physiologically identified interneurons in the dentate gyrus of urethane-anesthetized rats. Feedforward neurons were inhibited ( $\sim 1-2 \mathrm{~min})$ by locus ceruleus activation. Feedback interneurons showed both increased and decreased activity, whereas granule cells increased firing as predicted by evoked potential studies. EEG results replicated an increase in $\theta$ power $(4-8 \mathrm{~Hz})$ with locus ceruleus activation, but the effect with glutamatergic locus ceruleus activation was transient $(\sim 1-2 \mathrm{~min}) . \beta-\gamma$ Frequencies were also transiently suppressed. Together, the data suggest that locus ceruleus activation enhances the throughput of concomitant sensory input by reducing feedforward inhibitory interneuron activity, which may reduce "binding" in existing cell assemblies, and enhances the conditions for synaptic plasticity through disinhibition, promotion of $4-8 \mathrm{~Hz} \theta$, and noradrenergic potentiation to facilitate the building of new representations.
\end{abstract}

Key words: EEG; electroencephalogram; granule cell; hippocampus; interneuron; LTP; long-term potentiation; noradrenergic; norepinephrine; noradrenaline

\section{Introduction}

Arousal systems have roles in attention (Berridge and Waterhouse, 2003), reinforcement (Hebb, 1996), and learning and memory (Kety, 1970). The noradrenergic locus ceruleus, in particular, has been hypothesized to provide a signal that promotes synaptic plasticity (Kety, 1970). Exogenous or endogenous norepinephrine in the dentate gyrus promotes and permits longterm perforant path potentiation in vitro (Lacaille and Harley, 1985; Stanton and Sarvey, 1985, 1987; Sarvey et al., 1989) and in vivo (Neuman and Harley, 1983; Harley and Milway, 1986; Ezrokhi et al., 1999; Munro et al., 2001). Phasic locus ceruleus activation produces a delayed $(24 \mathrm{~h})$ protein synthesis-dependent long-term potentiation of synaptic plasticity, suggesting a selective role in long-term memory (Walling and Harley, 2004).

The locus ceruleus fires phasically to novel inputs (Vankov et al., 1995) and to changes in environmental contingencies (Sara et

Received 0ct. 16, 2004; revised Jan. 11, 2005; accepted Jan. 12, 2005

This work was supported by a grant from the Natural Sciences Research Council to C.W.H. We thank Dr. Richard Neuman for helpful input on a previous version of this manuscript.

Correspondence should be addressed to Carolyn W. Harley, Department of Psychology, Memorial University of Newfoundland, St. John's, Newfoundland, Canada A1B 3X9. E-mail: charley@mun.ca.

D01:10.1523/JNEUROSCI.4307-04.2005

Copyright $\odot 2005$ Society for Neuroscience $\quad$ 0270-6474/05/251985-07\$15.00/0 al., 1994; Vankov et al., 1995). Locus ceruleus activation by novelty is associated with increases in the perforant path-evoked population spike (Kitchigina et al., 1997). Glutamate infusion into locus ceruleus also phasically activates locus ceruleus neurons and is associated with an increased perforant path population spike (Harley and Sara, 1992). Glutamate infusion offers a tool for investigating the effects of phasic locus ceruleus activation.

Long-term potentiation of the perforant path-evoked field potential in the dentate gyrus after locus ceruleus activation (Harley and Milway, 1986; Harley and Sara, 1992; Kitchigina et al., 1997; Walling and Harley, 2004) or after reinforcer-induced switching from early-phase to late-phase tetanic long-term potentiation (Seidenbecher et al., 1997) is $\beta$-adrenoceptor dependent, consistent with a requirement for norepinephrine. Potentiation of the perforant path population spike by norepinephrine, the characteristic in vivo effect, could arise from increased granule cell excitability or reduced inhibition from interneurons on granule cells, or both.

Unit recording in the dentate gyrus shows, however, that exogenous norepinephrine inhibits granule cells and excites presumed inhibitory interneurons (Pang and Rose, 1987; Rose and Pang, 1989). Activation of $\alpha 2$ - or $\beta$-adrenoceptors excited interneurons and granule cells (Rose and Pang, 1989); $\alpha 1$ - 
adrenoceptor activation inhibited granule cells. Increased inhibitory interneuron activity and inhibition of granule cells is inconsistent with the enhanced granule cell responsiveness and enhanced plasticity in the dentate gyrus seen with population recording. An in vitro study (Bijak and Misgeld, 1995) also reports increased activity among presumed inhibitory interneurons by $\beta$-adrenoceptor activation but notes that $\beta$-adrenoceptor agonists acting at different sites in the network enhance inhibition, as well as excitation, of inhibitory interneurons. Thus, a critical question concerns the action of endogenous norepinephrine on the dentate gyrus interneurons.

This study used the response to perforant path input to physiologically identify feedforward interneurons in the dentate gyrus, which fire before granule cells and are activated at a lower threshold, and feedback interneurons, which fire only when granule cells are activated and follow granule cell activation, and assessed their response to glutamate ejections in the locus ceruleus of urethane-anesthetized rats. EEG activity was evaluated concurrently from the same microelectrodes.

\section{Materials and Methods \\ Urethane-anesthetized rats}

Data reported here were obtained from 19 male Sprague Dawley rats (250-700 g; Memorial University of Newfoundland Vivarium). Experimental procedures were performed in accordance with the Canadian Council of Animal Care guidelines following a protocol approved by the Institutional Animal Care Committee.

\section{Surgical procedures}

Animals were anesthetized ( $1.5 \mathrm{~g} / \mathrm{kg}$ urethane, i.p.) and fixed in a stereotaxic apparatus in the skull flat position. Marcaine with epinephrine $(0.2$ $\mathrm{ml}$ ) was injected into the scalp to provide local anesthesia and control bleeding. Rectal temperature was maintained between 36.5 and $37.5^{\circ} \mathrm{C}$. Holes were drilled over three locations: (1) dentate gyrus $(-3.5 \mathrm{~mm}$ posterior, $2.0 \mathrm{~mm}$ lateral to bregma), (2) perforant path ( $-7.2 \mathrm{~mm}$ posterior, $4.1 \mathrm{~mm}$ lateral to bregma), and (3) the locus ceruleus $(-12.6 \mathrm{~mm}$ posterior, $1.3 \mathrm{~mm}$ lateral to bregma).

\section{Electrode placements and recording}

A low-impedance recording electrode was placed in the dentate gyrus to assist with the placement of a concentric bipolar stimulating electrode (SNE-100; David Kopf Instruments, Tujunga, CA) in the perforant path. When a stimulation electrode placement optimal for a negative-going population spike was achieved, the low-impedance recording electrode was withdrawn.

The pressure ejection pipette directed at the locus ceruleus was filled with a combination of $500 \mathrm{~mm}$ glutamate (l-glutamic acid; SigmaAldrich, St. Louis, MO) and 2\% biocytin (biocytin hydrochloride; Sigma-Aldrich). Pipettes were mounted in pressure tubing connected to a pressure ejector (Neuro Phore BH-2; Medical Systems, Greenvale, NY) and fitted with a recording wire. Tip sizes were adjusted such that a nitrogen pressure pulse of $2-15 \mathrm{~ms}$ yielded a volume of $70-250 \mathrm{nl}$ measured in air. Previous work with radiolabeled glutamate has shown that intracerebral injections are $\sim 68 \%$ of those seen in air (Welzl et al., 1985). Pipette tips were $25-50 \mu \mathrm{m}$, with impedances of $<3 \mathrm{M} \Omega$. The pipette was advanced at a $20^{\circ}$ angle from the vertical to bypass the sagittal sinus.

The locus ceruleus was identified by the characteristic electrical silence that occurred after moving through the electrically noisy cerebellum. Recordings of cells of the pons that responded to jaw stretch and cells of the locus ceruleus that responded to tail pinch were used to assist in the placement of the ejection pipette, which was typically $6.0-6.5 \mathrm{~mm}$ below the surface. The low-impedance pipettes did not permit consistent identification of locus ceruleus neurons because the signal-to-noise ratio was low, but they did permit the identification of nearby landmarks and allowed auditory identification of responses to tail pinch.

In a previous study (Harley and Sara, 1992), locus ceruleus ejection of $50-100 \mathrm{nl}$ of $500 \mathrm{~mm}$ glutamate from pipettes or infusion of $100 \mathrm{nl}$ of 500 mM glutamate using a 33 gauge cannula produced a strong multiunit activation of locus ceruleus neurons that lasted $250-400 \mathrm{~ms}$ and was followed by $4-5 \mathrm{~min}$ of silence. Cells returned to normal baseline activity $(\sim 1 \mathrm{~Hz})$ after the silent period. Although depolarization block may occur after the glutamate ejection, the failure to see increased activity at the end of the silent period was inconsistent with this mechanism. Strong phasic norepinephrine release may produce enduring feedback inhibition in locus ceruleus through activation of $\alpha 2$ autoreceptors. Manipulations similar to those used here increased norepinephrine release in the hippocampus by $165 \%$ (Walling et al., 2004) in the first microdialysis sample after locus ceruleus glutamate infusion. The pattern of a brief $(<400 \mathrm{~ms})$ en masse firing episode in the locus ceruleus mimics that described in awake rats (Bouret and Sara, 2004); however, the long postactivation silence is not normally observed in physiological recordings of phasic activity, which are characterized by brief $(\sim 500 \mathrm{~ms})$ postactivation silent periods. The rate of firing during the glutamate-elicited phasic episode is likely close to the maximal rates reported for these neurons $(\sim 10-15$ $\mathrm{Hz}$ ). Rates of $10 \mathrm{~Hz}$ occur in physiological phasic episodes when two to three spikes may be seen in a $200-300$ ms period.

Dentate gyrus units were recorded with glass electrodes filled with $2 \%$ biocytin (Sigma-Aldrich) dissolved in $0.5 \mathrm{~m}$ potassium acetate. Electrodes had approximate tip sizes of $0.5-2 \mu \mathrm{m}$ and impedances of 5-25 $\mathrm{M} \Omega$ ex vivo. Electrodes were connected to dual HIP5 high-impedance head stages (Grass Instruments, Quincy, MA) fed into Grass P5 amplifiers. One channel was bandpass filtered $(600 \mathrm{~Hz}-10 \mathrm{kHz})$ and amplified for units; the second channel was bandpass filtered for either EEGs (0.1$300 \mathrm{~Hz}$ ) or evoked potentials $(1 \mathrm{~Hz}-3 \mathrm{kHz})$. The $60 \mathrm{~Hz}$ notch filter was taken out for evoked potentials. After a unit was isolated, it was recorded in conjunction with evoked potentials. Current pulses $(0.2 \mathrm{~ms})$ in the perforant path, which were subthreshold, at threshold, and suprathreshold for a population spike, were used to generate evoked potentials that permitted unit classification. Recordings of at least $1 \mathrm{~min}$ were taken at each current level with a $0.1 \mathrm{~Hz}$ stimulation rate. Recording continued until the unit fired spontaneously in the prestimulation portion of the record, so that the unit waveform was available for comparison purposes. Digitized units $(15 \mathrm{kHz})$, evoked potentials $(15 \mathrm{kHz})$, and EEGs $(256 \mathrm{~Hz})$ were retained for off-line analysis. After the evoked potential tests, the amplifier was adjusted to record EEGs, and perforant path stimulation was stopped.

A minimum of 5 min of spontaneous unit activity was recorded before glutamate ejection in the locus ceruleus (locus ceruleus activation). The dentate gyrus unit channel was monitored for spontaneous threshold crossings. Units were extracted from the record and recorded for off-line analysis. A pressure pulse was applied to the glutamate-containing pipette, and recording continued until either the unit returned to the baseline firing rate or $5 \mathrm{~min}$ had elapsed, whichever was longer.

At the termination of recording, the recording site was marked with an iontophoretic application of biocytin. Another recording electrode penetration could be made if the penetration was no closer than $300 \mu \mathrm{m}$ to the earlier track. No more than three sites were marked per animal, and no more than three units were isolated from the same animal.

At the conclusion of the experiment, animals were transcardially perfused with $300 \mathrm{ml}$ of heparinized $0.1 \mathrm{M}$ PBS, pH 7.4, followed by 200-300 $\mathrm{ml}$ of fixative consisting of $0.5 \%$ glutaraldehyde and $4 \%$ formaldehyde or paraformaldehyde in $0.1 \mathrm{M}$ PBS. The brains were cryoprotected and frozen for later sectioning.

Sagittal sections $(50 \mu \mathrm{m})$ of locus ceruleus and coronal sections ( 80 $\mu \mathrm{m})$ of the dentate gyrus were collected in ice-cold $0.1 \mathrm{~m}$ PBS. Sections were washed and then incubated with the avidin-biotin complex (Vectastain Elite; Vector Laboratories, Burlingame, CA) in $0.2 \%$ Triton X-100 (Sigma-Aldrich) for $16 \mathrm{~h}$ at $4^{\circ} \mathrm{C}$. Sections were again washed and developed with diaminobenzidine (DAB substrate kit; Vector Laboratories); after a final wash, they were mounted on gelatin-coated slides. After airdrying, sections were further dehydrated in a graded series of alcohols, cleared in xylene, and coverslipped. Some sections were rehydrated and counterstained with cresyl violet before being dehydrated and mounted.

\section{Data analysis}

Unit data. Unit waveforms were cluster cut and assembled into ratemeter histograms using tools included with Datawave (Boulder, CO). Unit firing rates for each $1 \mathrm{~s}$ period were summed. Burst events, defined 


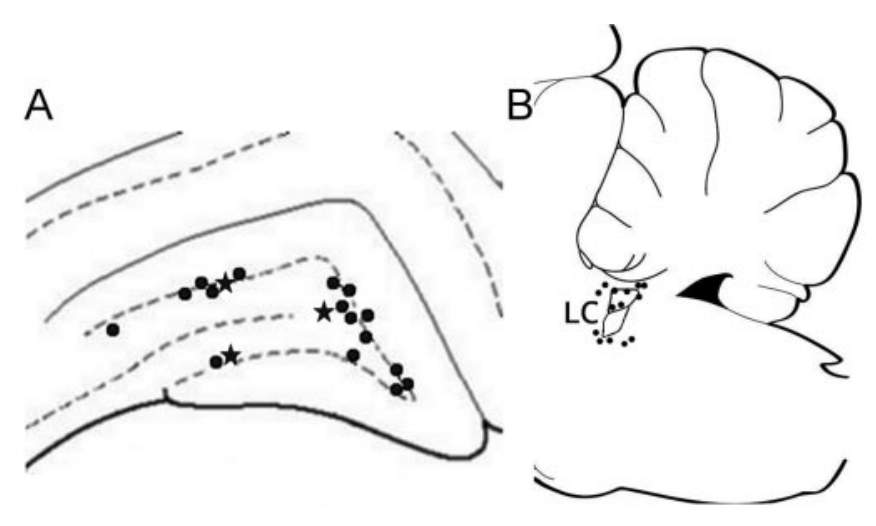

Figure 1. Recording $(\boldsymbol{A})$ and glutamate ejection $(\boldsymbol{B})$ pipette placements. All recording sites were located in the perigranular or hilar zone of the dentate gyrus. Sites with a star indicate the locations of feedback interneurons excited by locus ceruleus (LC) activation. All other interneurons were inhibited by locus ceruleus activation. Ejection pipette placements were located in the locus ceruleus or in the pericerulear zone.

as spikes occurring within $6 \mathrm{~ms}$ of each other, were counted. Autocorrelations were also examined. The averaging of units within a cluster and examination of the average waveform determined amplitudes and widths of unit waveforms. Width was taken as the time between the peak waveform positivity and negativity. Waveform amplitudes were taken as the voltage difference between the peak positivity and the peak negativity divided by the amplification.

The averaged waveform was also used to calculate the waveform asymmetry ratio of the leading peak or valley for each cell. Asymmetry was expressed as the ratio of the rise time from $20 \%$ maximum to maximum divided by the fall time from maximum voltage to $20 \%$. This parameter differentiates among hippocampal interneurons and principal cells (Henze et al. 2002).

EEG. The EEG records were analyzed using the fast Fourier transform utility of Datawave. Samples taken within a $30 \mathrm{~s}$ interval were averaged for calculation of absolute and relative EEG power in discrete ranges from 1 to $80 \mathrm{~Hz}$ as well as total power from 0 to $128 \mathrm{~Hz}$.

\section{Final placements}

All recovered recording placements for individual cells (19 of 27) were located in the dentate gyrus. Seventeen of the 19 placements were in the granular-subgranular zone (Fig. $1 A$ ). Three placements were recovered in the lower blade. Three placements were recovered in the most medial portion of the hilus. No placements were recovered in the molecular layer. Photomicrographs illustrating biocytin ejection sites for the recording placements of interneurons and a granule cell are shown in Figure 2. Typically multiple cells were labeled near a small cloud of biocytin that was taken as the recording tip. In one case, a granule cell was exclusively labeled. Physiologically, the recorded cell at that site met the criteria of a granule cell (Fig. 2D).

All recovered glutamate ejection placements (14 of 19 animals) were within $500 \mu \mathrm{m}$ of the edge of the locus ceruleus and well placed to activate locus ceruleus soma or dendrites (Fig. $1 \mathrm{~B}$ ). Four placements were within the locus ceruleus; another five were ventromedial to locus ceruleus in the subcerulear area. Two placements were anteromedial to locus ceruleus, two were dorsal, and one was on the posterior margin (Fig. 2E). The most distant recovered placement was in the magnocellular portion of the medial vestibular nucleus $\sim 400 \mu \mathrm{m}$ ventral and $300 \mu \mathrm{m}$ posterior to the locus ceruleus. A photomicrograph of one ejection site indicating the spread of the biocytin-glutamate mixture in the posterior locus ceruleus is shown in Figure 2.

Cells and glutamate ejection sites were not always located anatomically because of processing difficulties with the tissue or when multiple ejections were used from the same recording pipette. When cell-recording profiles and responses were similar to those seen at the sites identified in Figure 1, they were included in the data analysis. Ejection sites more remote from the locus ceruleus, as reported previously for evoked potentials (Harley and Milway, 1986), did not alter cell recordings.

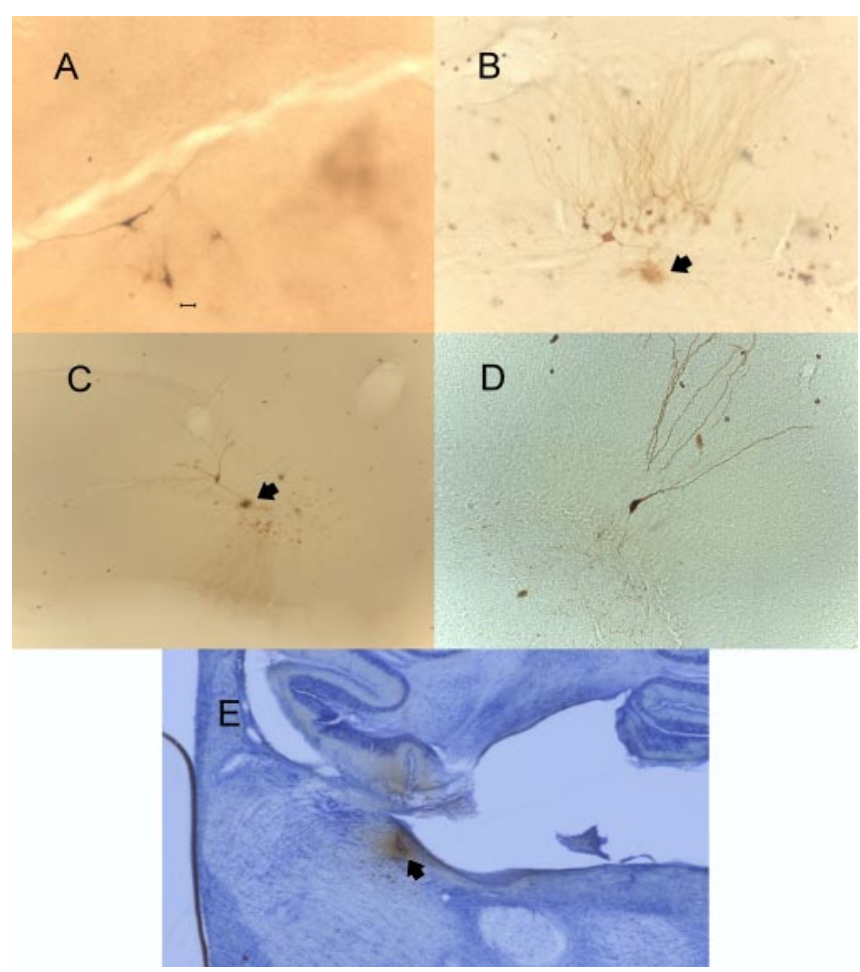

Figure 2. Photomicrographs of biocytin ejections sites in the dentate gyrus for a feedback interneuron excited by locus ceruleus activation (A); a feedback interneuron inhibited by locus ceruleus activation (arrowhead denotes presumed biocytin iontophoretic site) $(\boldsymbol{B})$; a feedforward interneuron inhibited by locus ceruleus activation with presumed iontophoretic site marked by an arrowhead ( $(\boldsymbol{C})$; a granule cell excited by locus ceruleus activation (D). Scale bars: (in $A) A, B, D, 20 \mu \mathrm{m} ; C, 40 \mu \mathrm{m}$. $E$, A photomicrograph for a glutamate-biocytin ejection in the posterior locus ceruleus. The micropipette track can be seen in lower cerebellum and posterior locus ceruleus. The black arrow indicates the locus ceruleus.

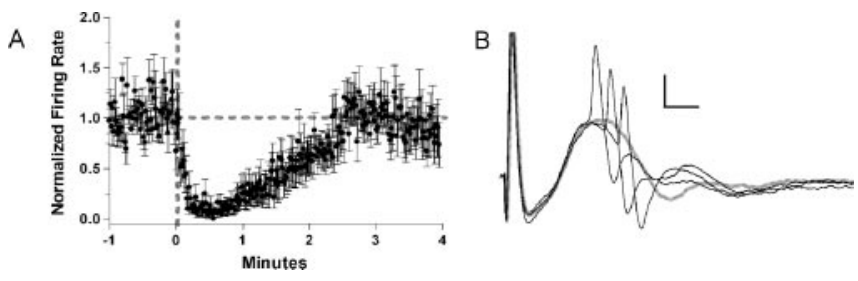

Figure 3. A, Normalized firing rate of 16 feedforward cells. Thick gray dotted lines indicate the baseline firing rate and time of ejection. The averaged firing rate drops to $\sim 0$ shortly after the ejection and then returns to baseline by $3 \mathrm{~min}$. Thin black lines indicate SE. $B$, Example of a feedforward cell. The cell discharges reliably at a current below that necessary to produce a population spike. When the current was increased, the cell discharged earlier than the population spike. A failure is shown in gray. Calibration: $80 \mu \mathrm{V}, 2 \mathrm{~ms}$.

\section{Results}

\section{Differential regulation of dentate gyrus units by locus} ceruleus activation

\section{Feedforward interneurons}

Eighteen neurons from 13 animals were driven by perforant path stimulation to fire in the absence of a population spike and with a latency shorter than that of the population spike and thus were classified as feedforward interneurons. The mean firing rate (5.6 $\mathrm{Hz}$ ) of 16 of 18 feedforward interneurons was significantly reduced by glutamate ejection in the vicinity of the locus ceruleus (Fig. 3). The two feedforward interneurons that were not significantly reduced by locus ceruleus activation decreased their firing rates after activation but had very low and variable baseline activity (mean firing rate $=0.02 \mathrm{~Hz}$ ). Ten of the 18 interneurons 

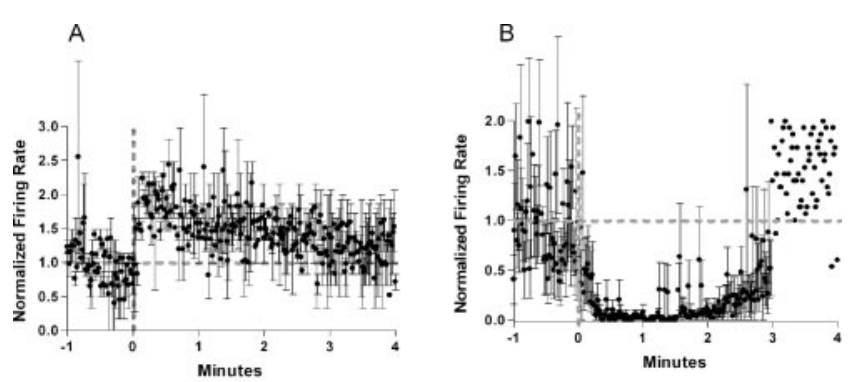

C

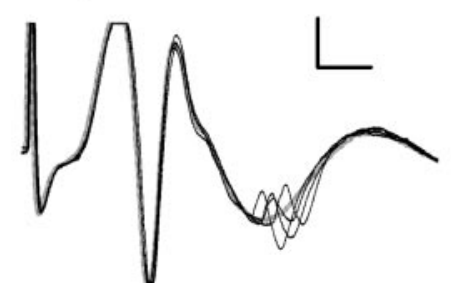

Figure 4. A, Normalized firing rate of the three feedback cells excited by locus ceruleus activation. The averaged firing rate doubles almost immediately after ejection and returns to baseline by $3 \mathrm{~min}$. Thick gray dotted lines indicate the baseline firing rate and time of ejection. Thin black lines indicate SE. $\boldsymbol{B}$, Normalized firing rate of two of the four feedback cells inhibited by locus ceruleus activation. The two cells that were omitted had baseline firing rates of $<1 \mathrm{~Hz}$. The averaged firing rate drops to 0 and then shows recovery of firing between 2 and 3 min. $C$, Example of a feedback cell. The cell would discharge only at currents sufficient to evoke a robust population spike. A failure is shown in gray. Calibration: $100 \mu \mathrm{V}, 2 \mathrm{~ms}$.

had $>1 \%$ of spikes in burst events in the 5 min before glutamate ejection $($ mean $=12.8 \%$ ). This did not change in the 5 min after glutamate ejection $($ mean $=11.5 \%)$. Narrow waveform cells (see below, Cell sorting analysis) were unlikely to have spikes in burst events (four of five).

\section{Feedback interneurons}

Seven neurons in seven animals were driven to fire only when currents were sufficient to evoke a population spike. Unit latencies also exceeded that of the population spike. These neurons were classified as feedback interneurons. Three units (mean firing rate $=8.6 \mathrm{~Hz}$ ) were excited by glutamate ejection into the locus ceruleus (Fig. 4). Four units (mean firing rate $=3.9 \mathrm{~Hz}$ ) were inhibited by locus ceruleus activation. The firing pattern for the two inhibited units with baseline firing of $>1 \mathrm{~Hz}$ is shown in Figure 4. The two units with baseline rates $<1 \mathrm{~Hz}$ are not included in Figure 4.

\section{Granule cells}

Two neurons in two rats were driven only when the current was sufficient to evoke a population spike and the threshold for activating the two cells and eliciting population spikes was identical. The firing latencies were such that firing fell during the evoked population spike. For one recording site, the biocytin labeling also revealed only a single granule cell (Fig. $2 D$ ). These cells were classified as granule cells. The granule cells had low firing rates (mean firing rate $=0.2 \mathrm{~Hz}$ ) and were excited strongly by locus ceruleus activation (Fig. 5). Both of these neurons had spikes in burst events after locus ceruleus activation (mean $=12.5 \%$ ).

\section{Autocorrelation patterns}

To examine rhythmic oscillations for each cell type, autocorrelations using 2-5 ms bins and varying time frames were performed for all cells for the $5 \mathrm{~min}$ before and the $5 \mathrm{~min}$ after locus ceruleus activation. The three feedback interneurons excited by locus ceruleus activation showed either an increase in or the appearance of
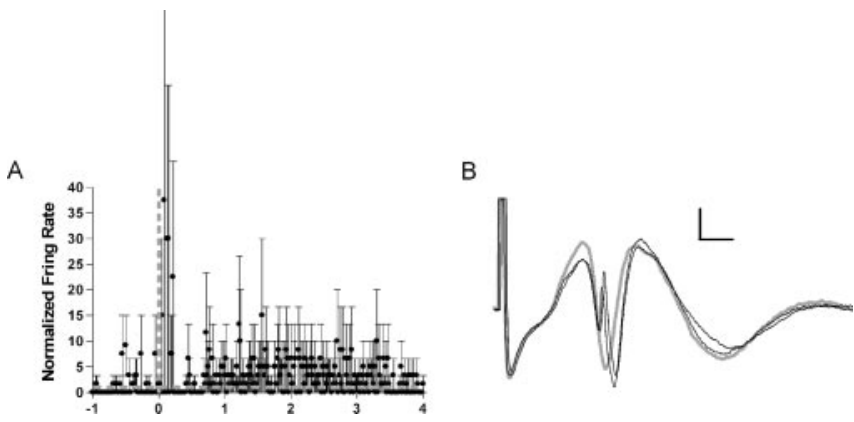

Figure 5. A, Normalized firing rate of two granule cells. Thick gray dotted lines indicate the baseline firing rate and time of ejection. The averaged firing rate increases rapidly after ejection and then rapidly returns to baseline. There is a suggestion of increased activity at longer time periods. Relative firing rates are high for these cells because the baseline rate is low. Thin black lines indicate SE. $\boldsymbol{B}$, An example of a granule cell. The cell discharge occurs at the same current necessary to evoke a population spike and at the same latency as the population spike. A failure is depicted in gray. Calibration: $200 \mu \mathrm{V}, 2 \mathrm{~ms}$.

$\beta$ or $\gamma$ oscillations in the $5 \mathrm{~min}$ after locus ceruleus activation. Autocorrelations for two of these cells are shown in Figure 6, A and $C$. One of the four inhibited feedback interneurons showed $\beta$ activity before and after locus ceruleus activation, although the oscillations were smaller and slower after activation (Fig. 6B). A feedforward interneuron also exhibited $\beta$ oscillations in the 5 min period before locus ceruleus activation. Slower oscillations were more common with 16 interneurons showing slower oscillations of $\sim 2 \mathrm{~Hz}$ (nine cells) (Fig. $6 B, C, E$ ), $3 \mathrm{~Hz}$ (four cells) or 4 $\mathrm{Hz}$ (three cells) (Fig. 6D). These could co-occur with faster oscillations, as seen in Figure 6, $B$ or $C$, or occur without faster oscillations. There was no consistent relationship between locus ceruleus activation and the occurrence of the slower oscillations. EEG data were examined for eight cells that showed pronounced $\delta$ oscillations $(1-3 \mathrm{~Hz})$. There was no significant change in $\delta$ power with locus ceruleus activation. Interneurons could show a strong increase or decrease in $\delta$ oscillation after locus ceruleus activation, but global EEGs from the same electrode did not reflect these autocorrelation changes. Other cells (nine), including both granule cells and some of the inhibited feedforward and feedback interneurons, showed no oscillatory patterns and tended to fire at short interspike intervals of $\sim 10 \mathrm{~ms}$. This pattern was also characteristic of oscillating cells (Fig. 6D,F), with only seven cells (including the three excited feedback cells) showing an early pause (Fig. $6 A-C$ ), rather than a peak.

\section{Cell-sorting analysis}

Two criteria were used to differentiate cells: cell width and cell symmetry ratio. Plotting the cell width against the cell symmetry ratio yielded three distinct clusters (Fig. 7). One cluster was distinguished by narrow action potential widths $(489 \pm 53.6 \mu \mathrm{s})$ compared with the remaining two groups $(863.7 \pm 38.6$ and $\left.876.9 \pm 42.9 \mu \mathrm{s} ; F_{(2,24)}=21.4 ; p<0.0001\right)$. Post hoc tests revealed a difference only between narrow cells and the remaining two clusters (Scheffés test; $p<0.0001$ ). The remaining two clusters had roughly similar cell widths, but one cluster had a symmetry ratio of $\sim 1(1.02 \pm 0.033)$ and was termed symmetrical. The symmetry ratio of the third cluster was $<1(0.66 \pm 0.034)$, indicating a slow decay from peak relative to the rapid rise, and these were termed wide cells. Narrow cells had a symmetry ratio substantially $>1(1.32 \pm 0.061)$. Analysis of symmetry ratios revealed a significant main effect $\left(F_{(2,24)}=62.9 ; p<0.0001\right)$, with significant differences among all three comparisons in post hoc 
A

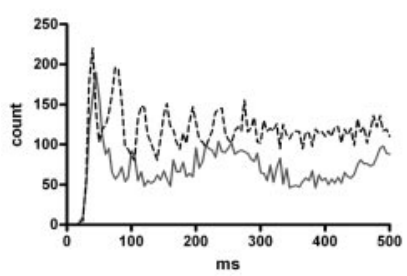

B

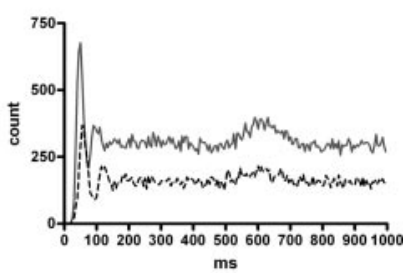

$\mathrm{ms}$
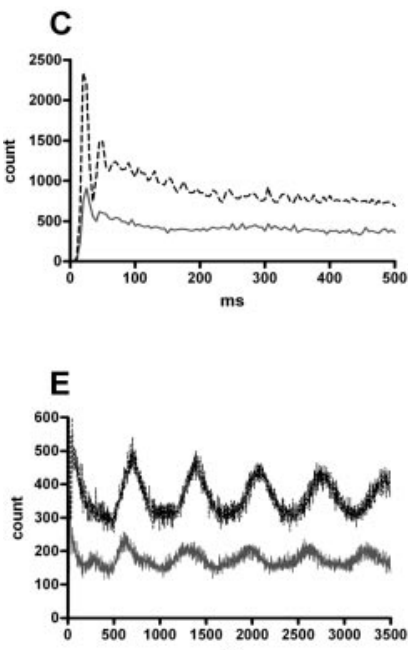

ms
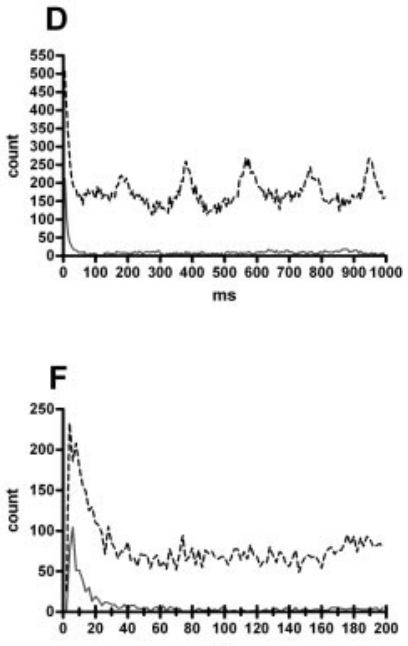

ms
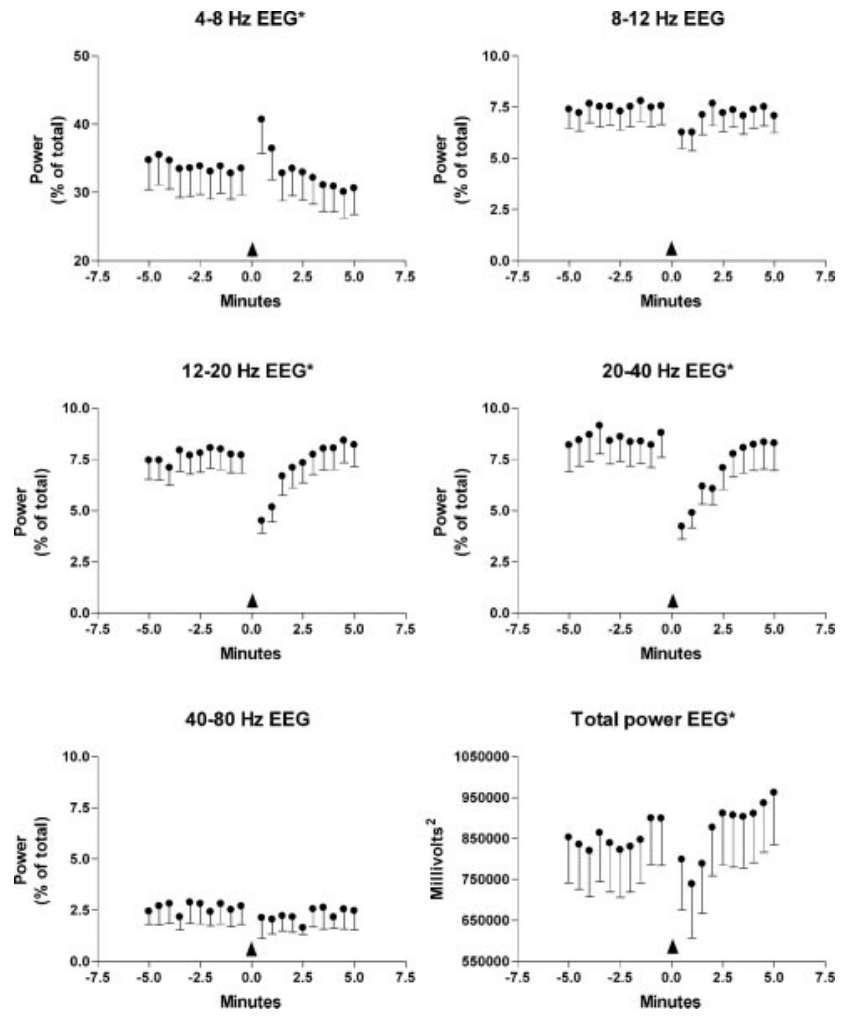

Figure 8. Relative EEG power expressed as a percentage of total in the indicated frequency ranges for 5 min before and after locus ceruleus activation by glutamate ejection $(n=18)$ in the locus ceruleus. The arrow indicates glutamate ejection. The bottom right-hand graph shows the variation in total power. Error bars indicate SE of the mean. ${ }^{*} p<0.05$; variation over time was significant in a repeated-measures ANOVA. activation (black line). $C$, Second feedback cell excited by locus ceruleus activation with an increase in $\gamma(40 \mathrm{~Hz})$ oscillations (black line). Note that the time scale is expanded. The recording site for this cell is shown in Figure 2A.D, Feedforward cell inhibited by locus ceruleus activation with an increase in $\theta$ oscillations in the 5 min period after activation (black line). $\boldsymbol{E}$, Longer time span for the cell shown in $\boldsymbol{C}$ to highlight the $\theta$ rhythm $(1.4 \mathrm{~Hz})$ that also increases after locus ceruleus activation. $\boldsymbol{F}$, An expanded time scale for the cell shown in $\boldsymbol{D}$ to show the peak of short interval activity characteristic of the majority of feedforward interneurons. In all graphs, the black line reflects the autocorrelation in the $5 \mathrm{~min}$ after locus ceruleus activation, whereas the gray line reflects the autocorrelation in the $5 \mathrm{~min}$ before locus ceruleus activation. The autocorrelations shown were performed with $5 \mathrm{~ms}$ bins.

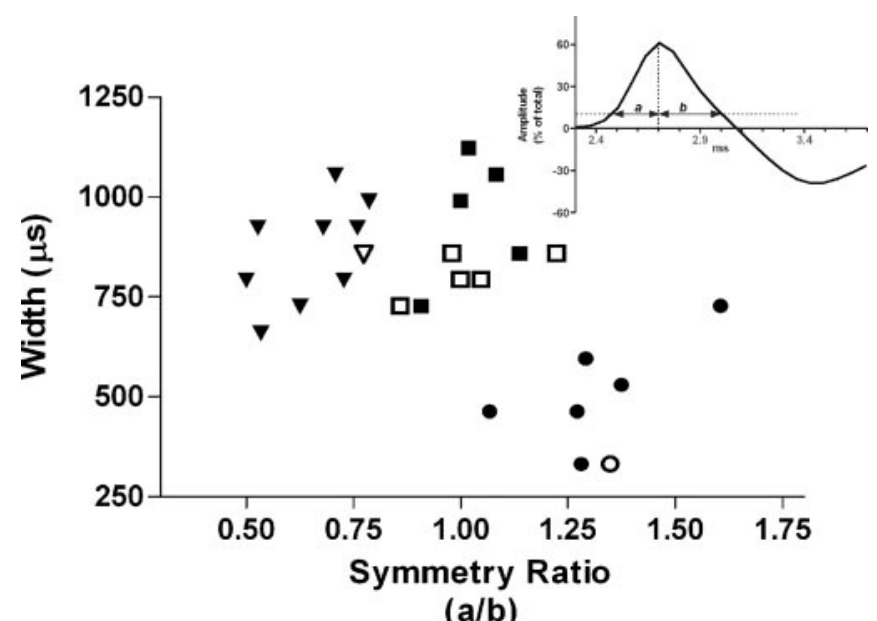

Figure 7. Cell classification. Cells were clustered using two parameters: peak-to-peak cell width and symmetry ratio. Cells appear to form three distinct clusters. Most of the feedback cells (hollow symbols) occur in a single cluster. Inverted triangle, Wide cells; circle, narrow cells; square, symmetric cells. Inset, Graph depicting determinant of symmetry ratio. Symmetry represents the ratio of rise time (a) over fall time (b) for the positive portion of the waveform. tests (Scheffe's test; $p=0.0002$ ). Most of the feedback cells (five of seven) fell into the symmetrical cluster. A single feedback cell appeared in each of the narrow and wide categories. The narrowest cells were predominately feedforward (five of seven cells), as were the wide cells (eight of nine cells). Putative granule cells fell in both the narrow and wide clusters.

\section{EEGs in urethane-anesthetized rat}

EEG modulation was assessed $(n=27)$ after locus ceruleus activation in 19 animals (Fig. 8). Total power was significantly decreased for $1.5 \mathrm{~min}$ after locus ceruleus activation $\left(F_{(19,456)}=\right.$ $2.91 ; p<0.00005)$. Relative $\theta$ power in the $4-8 \mathrm{~Hz}$ range increased for $1.5 \mathrm{~min}$ after locus ceruleus activation $\left(F_{(19,456)}=\right.$ $2.61 ; p<0.0005)$. Relative $\theta$ power in the $8-12 \mathrm{~Hz}$ range decreased for $1.5 \mathrm{~min}$ after locus ceruleus activation, but this was not significant $\left(F_{(19,456)}=1.55 ; p<0.063\right)$. Relative $\beta$ power in the $12-20 \mathrm{~Hz}$ range $\left(F_{(19,456)}=4.96 ; p<0.00005\right)$, relative $\gamma$ power in the $20-40 \mathrm{~Hz}$ range $\left(F_{(19,456)}=4.56 ; p<0.00005\right)$, and relative $\gamma$ power in the $40-80 \mathrm{~Hz}$ range $\left(F_{(19,456)}=2.64 ; p<0.0005\right) \mathrm{de}-$ creased significantly during the $2-2.5 \mathrm{~min}$ after glutamate infusion in the locus ceruleus $\left(F_{(19,456)}=4.96 ; p<0.00005\right)$.

\section{Discussion}

Our study found that putative release of norepinephrine reduced interneuron activity in the dentate gyrus, in contrast to previous reports of increased interneuron activity with exogenous norepinephrine. Transient inhibition was observed in all physiologically identified feedforward interneurons. Inhibition of feedforward inhibitory interneuron activity would enhance perforant path input arriving concurrently, or shortly after, locus ceruleus acti- 
vation. Because novel events or changes in environmental contingencies phasically and synchronously activate locus ceruleus neurons, this circuitry provides a mechanism for amplifying potentially important inputs and is consistent with an attentional role for the noradrenergic system.

The effect of locus ceruleus activation on the smaller sample of feedback interneurons suggests that there are at least two functionally distinct populations of feedback interneurons, one excited by and one inhibited by locus ceruleus activation. Cell cluster data indicate that it may be possible to use waveform signatures, such as symmetry, to tentatively identify feedback interneurons, whereas narrow and wide asymmetrical waveforms are more typical of feedforward interneurons.

The strong increase in firing of putative granule cells is consistent with the decrease of activity in feedforward interneurons, which are likely to be inhibitory (Buzsaki, 1984). Strong granule cell activity could then drive the excited feedback interneurons; however, Sara and Bergis (1991) report that norepinephrine can enhance feedback inhibition in the dentate gyrus, even when granule cell excitability is unchanged. The subgroup of inhibited feedback interneurons cannot be readily accounted for by an increase in granule cell activity.

Although the dense plexus of noradrenergic fibers in the subgranular zone of the dentate gyrus (Blackstad et al., 1967; Loy et al., 1980) is consistent with the hypothesized importance of interneurons as a target for locus ceruleus input (Buzsaki, 1984), in this study it is not possible to know whether the effects of locus ceruleus activation are caused by direct or indirect consequences of norepinephrine release. What the cellular data suggest is that processing is altered in a regular pattern. The consistency of feedforward interneuron inhibition across experiments, despite variations in pipette placement and ejection volume in the locus ceruleus, indicates that this effect may require only some threshold level of locus ceruleus activation.

A previous study of the electrical stimulation effects of locus ceruleus on presumed granule cell activity in the dentate gyrus described inhibition of granule cells (Segal and Bloom, 1976), but the relative high firing rates of the cells studied are also consistent with their classification as interneurons. The use of electrical stimulation may be another source of difference in outcome, because electrical stimulation in the locus ceruleus area can produce effects not dependent on noradrenergic mediation (Harley et al., 1989; Branchereau et al., 1996).

Intracellular recordings of identified granule cells after exogenous norepinephrine reveal a modest depolarization (Lacaille and Schwartzkroin, 1988). This would promote cell firing and is consistent with our findings.

Exogenous norepinephrine and evoked release of norepinephrine may also differ in important ways. The iontophoretic application of norepinephrine produces either excitation or inhibition at the same cell in the dentate gyrus depending on placement of the iontophoretic pipette (Lacaille and Schwartzkroin, 1988). Norepinephrine also generates actions mediated by different adrenergic receptors, depending on the route of application, i.e., exogenous or endogenous (Curet and De Montigny, 1988). These differences, related to route of application, may contribute to discrepancies between present findings and previous studies investigating interneurons. Alternatively, previous studies may have selectively sampled from the feedback interneurons that are excited by noradrenergic release.

The transient depression of $\beta$ and $\gamma$ oscillations in the EEG after phasic locus ceruleus activation suggests that the coincident inhibition of feedforward interneurons diminishes power in higher-frequency oscillations. Changes in the rates of interneuron firing have been shown previously to modulate EEG power in hippocampus (Nitz and McNaughton, 1999). $\beta$ Frequency oscillations are associated with driving by interactions among brain structures (Kopell et al., 2000), which would be consistent with the direct modulation of feedforward interneurons by entorhinal input. $\gamma$ Oscillations can also be long range.

In the autocorrelations, $\beta$ or $\gamma$ oscillations were seen in some of each interneuron subtype. These higher-frequency oscillations increased with locus ceruleus activation in the excited feedback interneuron subgroup, suggesting another differential noradrenergic effect on interneuron subpopulations.

Noradrenergic suppression of $\gamma$ waves has been described recently in hippocampus in vitro, but a $\beta$-adrenergic agonist in the same preparation enhanced $\gamma$ activity (LeBeau et al., 2005), consistent with our observation of subpopulation differences. Because $\theta$ power increases during the suppression of feedforward interneurons, the excited feedback interneurons are the most likely candidates to provide the driving force for that increase.

Previous EEG experiments using cholinergic stimulation of locus ceruleus in halothane-anesthetized rats to evoke norepinephrine release found a decrease in total EEG power and an increase in the relative power of the $2.6-6.8 \mathrm{~Hz} \theta$ range (Berridge and Foote, 1991), similar to the changes seen here (Berridge and Wifler, 2000). With cholinergic activation, the time course of the EEG change closely followed increased locus ceruleus firing, lasting 10-15 min. In our study, effects were transient, as would be expected with phasic locus ceruleus activation.

The noradrenergic release properties of phasic locus ceruleus activation may account for the decreases in $\beta$ and $\gamma$ oscillations seen here but not observed previously (except as a part of the decrease in total power). Phasic locus ceruleus activation releases larger amounts of norepinephrine per spike than does an increase in tonic rate (Florin-Lechner et al., 1996).

The $4-8 \mathrm{~Hz} \theta$ rhythm supports $\theta$-burst long-term potentiation (Buzsaki, 2002), a quasi-naturalistic model of synaptic potentiation implicated in learning and memory. Together, the pattern of unit and EEG changes in the present study suggests that phasic activation of the locus ceruleus promotes new associations by feedforward disinhibition that enhances input and increases granule cell depolarization and by increasing $\theta$-mediated synaptic plasticity and reducing "binding" oscillations hypothesized to stabilize older associative patterns (Csicsvari et al., 2003; Buzsaki and Draguhn, 2004). Contingency windows for inputs would widen and the incorporation of new or altered input into hippocampal networks would be facilitated. A gating role for the inhibition of feedforward neurons in the promotion of long-term potentiation has been demonstrated in lateral amygdala (Bissiere et al., 2003). A "reset" function for the locus ceruleus has also been proposed based on the monitoring of locus ceruleus and forebrain unit activity in awake rats during olfactory learning (Bouret and Sara, 2004).

Seidenbecher et al. (2003) suggest that enhanced $\theta$ rhythms across limbic structures are critical for memory retrieval. A role for the noradrenergic system in retrieval (Przybyslawski et al., 1999 ) is consistent with the EEG changes seen here.

In awake rats exploring novel objects, an increase in the perforant path-evoked population spike dependent on $\beta$-adrenoceptors is observed for $\sim 1 \mathrm{~min}$ (Kitchigina et al., 1997). This increase is likely related to phasic firing of locus ceruleus, which accompanies novel object exploration, silencing feedforward interneurons as in this study. Rats moving into novel environments also show dramatic and transient disinhibition of unit 
activity in hippocampus (Wilson and McNaughton, 1993), and evoked potential parameters, such as population spike amplitude, are elevated (Kitchigina et al., 1997).

We conclude that activation of the locus ceruleus by glutamate results in multiple actions on the dentate gyrus that include but are not limited to a decrease in feedforward inhibition, an increase in $4-8 \mathrm{~Hz} \theta$ rhythm, a decrease in $\beta$ and $\gamma$ frequencies, and the promotion of long-term synaptic plasticity. Together, these actions facilitate the incorporation of novel information into a new neural representation. The activation of the locus ceruleus, specifically at such times, reinforces the hypothesis that norepinephrine modulation is part of a coordinated system to enhance behavioral adaptation to new circumstances (Bouret and Sara, 2004).

\section{References}

Berridge CW, Foote SL (1991) Effects of locus ceruleus activation on electroencephalographic activity in neocortex and hippocampus. J Neurosci 11:3135-3145.

Berridge CW, Waterhouse BD (2003) The locus coeruleus-noradrenergic system: modulation of behavioral state and state-dependent cognitive processes. Brain Res Brain Res Rev 42:33-84.

Berridge CW, Wifler K (2000) Contrasting effects of noradrenergic $\beta$-receptor blockade within the medial septal area on forebrain electroencephalographic and behavioral activity state in anesthetized and unanesthetized rat. Neuroscience 97:543-552.

Bijak M, Misgeld U (1995) Adrenergic modulation of hilar neuron activity and granule cell inhibition in the guinea-pig hippocampal slice. Neuroscience 67:541-550.

Bissiere S, Humeau Y, Luthi A (2003) Dopamine gates LTP induction in lateral amygdala by suppressing feedforward inhibition. Nat Neurosci 6:587-592.

Blackstad TW, Fuxe K, Hokfelt T (1967) Noradrenaline nerve terminals in the hippocampal region of the rat and the guinea pig. Z Zellforsch Mikrosk Anat 78:463-473.

Bouret S, Sara SJ (2004) Reward expectation, orientation of attention and locus coeruleus-medial frontal cortex interplay during learning. Eur J Neurosci 20:791-802

Branchereau P, Van Bockstaele EJ, Chan J, Pickel VM (1996) Pyramidal neurons in rat prefrontal cortex show a complex synaptic response to single electrical stimulation of the locus coeruleus region: evidence for antidromic activation and GABAergic inhibition using in vivo intracellular recording and electron microscopy. Synapse 22:313-331.

Buzsaki G (1984) Feed-forward inhibition in the hippocampal formation. Prog Neurobiol 22:131-153.

Buzsaki G (2002) Theta oscillations in the hippocampus. Neuron 33:325-340.

Buzsaki G, Draguhn A (2004) Neuronal oscillations in cortical networks. Science 304:1926-1929.

Csicsvari J, Jamieson B, Wise KD, Buzsaki G (2003) Mechanisms of gamma oscillations in the hippocampus of the behaving rat. Neuron 37:311-322.

Curet O, De Montigny C (1988) Electrophysiological characterization of adrenoceptors in the rat dorsal hippocampus. II. Receptors mediating the effect of synaptically released norepinephrine. Brain Res 475:47-57.

Ezrokhi VL, Zosimovskii VA, Korshunov VA, Markevich VA (1999) Restoration of decaying long-term potentiation in the hippocampal formation by stimulation of neuromodulatory nuclei in freely moving rats. Neuroscience 88:741-753.

Florin-Lechner SM, Druhan JP, Aston-Jones G, Valentino RJ (1996) Enhanced norepinephrine release in prefrontal cortex with burst stimulation of the locus coeruleus. Brain Res 742:89-97.

Harley CW, Milway JS (1986) Glutamate ejection in the locus coeruleus enhances the perforant path-evoked population spike in the dentate gyrus. Exp Brain Res 63:143-150.

Harley CW, Sara SJ (1992) Locus coeruleus bursts induced by glutamate trigger delayed perforant path spike amplitude potentiation in the dentate gyrus. Exp Brain Res 89:581-587.

Harley C, Milway JS, Lacaille JC (1989) Locus coeruleus potentiation of dentate gyrus responses: evidence for two systems. Brain Res Bull 22:643-650.

Hebb DO (1996) Textbook of psychology. Philadelphia: Saunders.

Henze DA, Wittner L, Buzsaki G (2002) Single granule cells reliably discharge targets in the hippocampal CA3 network in vivo. Nat Neurosci 5:790-795.

Kety SS (1970) Biological concomitants of affective states and their possible role in memory processes. In: The neurosciences: second study program (Schmitt FO, ed), pp 324-336. New York: Rockefeller UP.

Kitchigina V, Vankov A, Harley C, Sara SJ (1997) Novelty-elicited, noradrenaline-dependent enhancement of excitability in the dentate gyrus. Eur J Neurosci 9:41-47.

Kopell N, Ermentrout GB, Whittington MA, Traub RD (2000) Gamma rhythms and beta rhythms have different synchronization properties. Proc Natl Acad Sci USA 97:1867-1872.

Lacaille JC, Harley CW (1985) The action of norepinephrine in the dentate gyrus: beta-mediated facilitation of evoked potentials in vitro. Brain Res 358:210-220.

Lacaille JC, Schwartzkroin PA (1988) Intracellular responses of rat hippocampal granule cells in vitro to discrete applications of norepinephrine. Neurosci Lett 89:176-181.

LeBeau FEN, Racca C, Haggerty C, Partington MA, Whittington MA (2005) Noradrenaline modulates gamma frequency $(30-80 \mathrm{~Hz})$ oscillations in the rat hippocampus in vitro. Paper presented at the Physiological Society Meetings, Seville, Spain, February.

Loy R, Koziell DA, Lindsey JD, Moore RY (1980) Noradrenergic innervation of the adult rat hippocampal formation. J Comp Neurol 189:699-710.

Munro CA, Walling SG, Evans JH, Harley CW (2001) Beta-adrenergic blockade in the dentate gyrus in vivo prevents high frequency-induced long-term potentiation of EPSP slope, but not long-term potentiation of population spike amplitude. Hippocampus 11:322-328.

Neuman RS, Harley CW (1983) Long-lasting potentiation of the dentate gyrus population spike by norepinephrine. Brain Res 273:162-165.

Nitz DA, McNaughton BL (1999) Hippocampal EEG and unit activity responses to modulation of serotonergic median raphe neurons in the freely behaving rat. Learn Mem 6:153-167.

Pang K, Rose GM (1987) Differential effects of norepinephrine on hippocampal complex-spike and theta-neurons. Brain Res 425:146-158.

Przybyslawski J, Roullet P, Sara SJ (1999) Attenuation of emotional and nonemotional memories after their reactivation: role of $\beta$ adrenergic receptors. J Neurosci 19:6623-6628.

Rose GM, Pang KC (1989) Differential effect of norepinephrine upon granule cells and interneurons in the dentate gyrus. Brain Res 488:353-356.

Sara SJ, Bergis O (1991) Enhancement of excitability and inhibitory processes in hippocampal dentate gyrus by noradrenaline: a pharmacological study in awake, freely moving rats. Neurosci Lett 126:1-5.

Sara SJ, Vankov A, Herve A (1994) Locus coeruleus-evoked responses in behaving rats: a clue to the role of noradrenaline in memory. Brain Res Bull 35:457-465.

Sarvey JM, Burgard EC, Decker G (1989) Long-term potentiation: studies in the hippocampal slice. J Neurosci Methods 28:109-124.

Segal M, Bloom FE (1976) The action of norepinephrine in the rat hippocampus. III. Hippocampal cellular responses to locus coeruleus stimulation in the awake rat. Brain Res 107:499-511.

Seidenbecher T, Reymann KG, Balschun D (1997) A post-tetanic time window for the reinforcement of long-term potentiation by appetitive and aversive stimuli. Proc Natl Acad Sci USA 94:1494-1499.

Seidenbecher T, Laxmi TR, Stork O, Pape HC (2003) Amygdalar and hippocampal theta rhythm synchronization during fear memory retrieval. Science 301:846-850.

Stanton PK, Sarvey JM (1985) Depletion of norepinephrine, but not serotonin, reduces long-term potentiation in the dentate gyrus of rat hippocampal slices. J Neurosci 5:2169-2176.

Stanton PK, Sarvey JM (1987) Norepinephrine regulates long-term potentiation of both the population spike and dendritic EPSP in hippocampa dentate gyrus. Brain Res Bull 18:115-119.

Vankov A, Herve-Minvielle A, Sara SJ (1995) Response to novelty and its rapid habituation in locus coeruleus neurons of the freely exploring rat. Eur J Neurosci 7:1180-1187.

Walling SG, Harley CW (2004) Locus ceruleus activation initiates delayed synaptic potentiation of perforant path input to the dentate gyrus in awake rats: a novel $\beta$-adrenergic- and protein synthesis-dependent mammalian plasticity mechanism. J Neurosci 24:598-604.

Walling SG, Nutt DJ, Lalies MD, Harley CW (2004) Orexin-A infusion in the locus ceruleus triggers norepinephrine (NE) release and NE-induced long-term potentiation in the dentate gyrus. J Neurosci 24:7421-7426.

Welzl H, Tolle TR, Huston JP (1985) Intracranial application of substances in the unrestrained, awake rat by pressure injection through glass micropipettes. J Neurosci Methods 13:1-8.

Wilson MA, McNaughton BL (1993) Dynamics of the hippocampal ensemble code for space. Science 261:1055-1058. 